Article

\title{
An Agent-Based Two-Stage Trading Model for Direct Electricity Procurement of Large Consumers
}

\author{
Jian Zhang ${ }^{1, *} \mathbb{0}$, Yanan Zheng ${ }^{2}$, Mingtao Yao ${ }^{2}$, Huiji Wang ${ }^{3}$ and Zhaoguang $\mathrm{Hu}^{3}$ \\ 1 Department of Electrical Engineering, Tsinghua University, Beijing 100084, China \\ 2 Energy Research Institute, Chinese Academy of Macroeconomic Research, Beijing 100038, China \\ 3 School of Electrical and Electronic Engineering, North China Electric Power University, Beijing 102206, China \\ * Correspondence: zhangjianam@126.com
}

Received: 6 August 2019; Accepted: 11 September 2019; Published: 14 September 2019

\begin{abstract}
Many electricity markets around the world are still at developmental and transitional stages. To complete the transition and achieve the key objectives of perfect market design, designers often choose direct electricity procurement of large consumers (LCs) as a pilot. The trading mechanism is critical because it lays the foundation for the exploration of formulating a trading model and the succeeding solution; however, the existing trading mechanisms of direct electricity procurement struggle to cope with new challenges that electric power systems are facing. This paper proposes a novel two-stage trading mechanism, considering both the fairness and efficiency of direct electricity procurement. Based on the proposed trading mechanism, an agent-based trading model with multiple participants is developed. The simulation results of the transactions between LCs and generation companies (GenCos) illustrate the feasibility and effectiveness of the proposed mechanism. With this mechanism, LCs and GenCos will have more choices in the trading process and can benefit from the reduction of the average market price. The two-stage trading model provides a new choice for market designers and participants of direct electricity procurement.
\end{abstract}

Keywords: direct electricity procurement; large consumers; multi-agent; trading mechanism; two-stage

\section{Introduction}

Electricity markets have been established in many countries around the world. Since the 1960s, when nearly all power was provided by vertically integrated utilities [1], many milestones have already been reached with the ultimate goal of achieving increasingly efficient and fair markets for electricity. However, the path to perfect market design is littered with many failed attempts [2]. Renewable energy generation, storage, demand management, and smart grid technologies are inducing changes in the power industry [3]. Considering emerging factors, well-designed markets are needed to enhance the reliable and economic operation and planning of the power system [4]. Not every electricity market in the world has made the transition to deal with these new problems $[5,6]$.

To complete the transition and achieve the key objectives of perfect market design, several major market models have been considered, including electricity pools and bilateral transactions [7]. A pool is a centralized marketplace where buyers and sellers are cleared with a market price under a specific form of auction. A bilateral transaction is a negotiable agreement between a buyer and a seller on energy price, volume, delivery time, and other related issues. Electricity pool prices are affected by many complex factors and change quickly, making it difficult for market designers and participants to accurately predict them [8]. Market participants recognize the importance of price risk management, and often enter into bilateral contracts to hedge against pool price volatility [9]. In addition, market designers often choose bilateral contracts as a pilot for electricity market reform [10,11]. 
As a typical form of bilateral contract, direct electricity procurement of large consumers (LCs) has been widely adopted by countries around the world [6,12-14]. Direct electricity procurements are arrangements between buyers and sellers, allowing an LC to buy electricity from the generation company (GenCo) at a price agreed to by both sides before its physical delivery. The bidding or auction strategies have been a research hotspot, not only for GenCos but for LCs. Generation companies need to maximize revenues, whereas LCs need to minimize costs of participating in the market through direct electricity procurement. The research on portfolio optimization problems of GenCos has investigated different aspects, such as strategic bidding [15,16], risk management $[17,18]$, and congestion charges [19]. For some LCs who have their own power plants with a small capacity, the optimal electricity procurement from the market with determined factors or uncertain information has been studied [20-23]. Competition in the contract market is crucial for LCs and GenCos, because with competition, both sides will be more actively involved in trading, which will make the contract electricity price more reasonable [24]. In this context, methods based on game theory have been used extensively to solve the optimal bilateral contracts problem formulated in different ways [12,25]. The aforementioned studies focus on the behaviors and strategies of LCs and GenCos. The trading mechanism in the direct electricity procurement market has not been examined thoroughly in the literature.

The trading mechanism for direct electricity procurement is critical because it lays the foundation for the exploration of formulating the strategy optimization model and the succeeding solution. Some bilateral models have been proposed to address the weaknesses of pool trading by mimicking some of the trading methods in traditional commodity markets [26]. A complex network-based model for the equilibrium of a bilateral electricity market was proposed in reference [27], in which the bargaining process was represented by the evolution of the network and the market equilibrium was judged by the convergence of the network. In reference [28], a systematic negotiation scheme was studied which can lead to a GenCo and a consumer reaching a mutually beneficial and risk-tolerable forward bilateral contract. The alternating-offers bargaining protocol was extended and applied to discover the equilibrium strategy in one-to-many and many-to-many negotiations in reference [29]. The equilibrium models using a conjectural variation approach were presented in reference [30], and with a hierarchical optimization method, the GenCos can self-dispatch and manage the contracts to meet demand from consumers in a bilateral market. In reference [31], a financial bilateral contract negotiation process using the Nash bargaining theory was analyzed to model a Pareto-efficient settlement point and predict negotiation outcomes under various conditions. To deal with the uncertainties, unknown parameters, and the dynamics of the electricity market, the supply function equilibrium model with a uniform price was considered in reference [32]; furthermore, a reinforcement learning method with non-cooperative multi-agent was utilized to find the optimal solution for the proposed Markov game model. From another perspective, the problems of the trading mechanism can be divided according to the number of participants in the negotiation on each side of the market. Generally, they are divided into one-to-one negotiation, one-to-many negotiation, and many-to-many negotiation, of which the first mode is studied as a bilateral bargaining problem and the second two are considered an auctioning problem [29]. A few pieces of research have discussed direct electricity procurement as an electricity auction [33-35]. Different market design features, such as the duration of bids, the number of bidding steps, and the elasticity of demand, will affect market performance and trading equilibrium to varying degrees.

Due to the market structure, market reform level, supervisory mechanism, and many other complex and changing factors, the existing trading mechanisms of direct electricity procurement struggle to cope with new challenges. Targeted trading mechanisms should be designed for countries in the process of market reform, such as China, which has a huge power industry [36,37]. Thus, this paper proposes a novel trading mechanism of direct electricity procurement, which includes two bidding stages, to provide a new choice for GenCos and LCs in the process of electricity market reform.

The rest of this paper is organized as follows: Section 2 describes direct electricity procurement, Section 3 depicts a trading mechanism of direct electricity procurement, Section 4 presents a case study and the results, and finally, concluding remarks are presented in Section 5. 


\section{Description of Direct Electricity Procurement}

\subsection{Bilateral Contracts and Direct Electricity Procurement}

Bilateral contracts are negotiable agreements on the quantity, price, and time of the trading of electricity between buyers and sellers. Therefore, a bilateral contract essentially involves participants and their agreements. Market participants consist of the buyer and the seller. The terms and conditions of the agreement between the buyer and the seller cover many aspects, such as start and end time, electricity price, volume, and variable power demand over the length of the contract [7]. Most bilateral contracts follow four types of contract; namely, forward contracts, future contracts, option contracts, and contracts for difference [9]. Forward contracts and future contracts are physical or financial contracts between buyers and sellers that specify the quantity of electricity to be traded on an exact future date at a price negotiated in the present. The obvious difference is the revocability of the contract. Forward contracts can be drawn according to the will of both sides, whereas future contracts can only be changed by selling contracts that have been bought or buying contracts that have been sold. With option contracts, the seller assumes the obligation, whereas the buyer has the right, but not the obligation, to buy or sell the electricity at a given price. In contracts for difference, the seller pays to the buyer when there is a positive difference; that is, when the price increases during the trading term. Otherwise, the buyer will pay the seller if the price falls.

Direct electricity procurement is subject to bilateral contracts and frequently chosen in the initial stage of electricity market reform. In practice, direct electricity procurement is usually carried out among LCs, who refer to electrical power users with relatively large power demand and electricity consumption, generally industrial users and large-scale commercial users. For these LCs, they have the option of negotiating and signing a contract with GenCos based on future demand. Generation companies sell a given amount and quality of electricity and get paid at a contract price from LCs within the time period (several weeks to months) stipulated in the contract. Electricity price is a key element in negotiations, especially in the most commonly adopted future contracts. Large consumers and GenCos negotiate the price for a specific amount of electricity which they will trade with different modes.

\subsection{Trading Modes of Direct Electricity Procurement}

Direct electricity procurement can be carried out in a variety of modes, depending on the negotiation methods and transaction terms. Large consumers and GenCos exchange the price information in a one-to-one, one-to-many, or many-to-many manner. The contractual intention reached by negotiations or by meeting the trigger conditions will be checked by the independent system operator (ISO). For the security of system operation, the ISO needs to verify that the transmission capacity of the system is sufficient to complete the transaction under the premise of system security. The following trading modes are common ones for direct electricity procurement.

\section{- Independent Negotiation}

In the independent negotiation mode, the amount and price of electricity traded are determined through independent negotiation between LCs and GenCos. After the initial transaction intention is reached by both sides, the contract will be checked by the ISO. If the security checks are approved, the contract will be confirmed, and future transactions will be made according to the contract. This mode is illustrated in Figure 1.

\section{- Centralized Order Matching}

Centralized order matching mode is carried out in the form of two-way bidding between LCs and GenCos. Participants declare the transaction volume and price through the electricity trading platform, and then the electricity trading institution (ETI) will conduct market clearing according to the reverse matching rule. The ISO will perform the security checks on the clearing result to form the final contract. 
The reverse matching rule is illustrated in Figure 2. Large consumers and GenCos submit information on the electricity trading platform. They tend to adjust submitted prices based on a reference price. The ETI ranks participants according to price information, with LCs in descending order of price and GenCos in ascending order of price. This creates two transaction queues, in which each pair is judged on whether it meets the trading requirements. If the LC offers higher than the GenCo, the pair is a viable trade pair. If the LC bids lower than the GenCo, the subsequent LCs and GenCos in each queue need not be further judged. The market clearing price is the arithmetical average of the declared prices of the LC and the GenCo in the last pair of successful transactions, and this clearing price will be used as the settlement price for all successful transactions.

\section{- $\quad$ Listing Transactions}

Through the electricity trading platform, LCs and GenCos could make an offer to the public with trading information. Any participant on the platform who meets the requirements is entitled to apply for the offer. After the security checks and confirmation of both sides, the offer and application will form the final transaction.

\section{- $\quad$ Other Modes}

The assignment of contract and the generation rights trade are two important supplementary forms of transaction mode. The assignment of contract refers to the electricity can be transferred through contracts when the participant needs to adjust the signed medium- and long-term trading electricity. The assignee continues to perform the remainder of the contract. The generation rights trade refers to the assignment of contract between GenCos on the supply side.

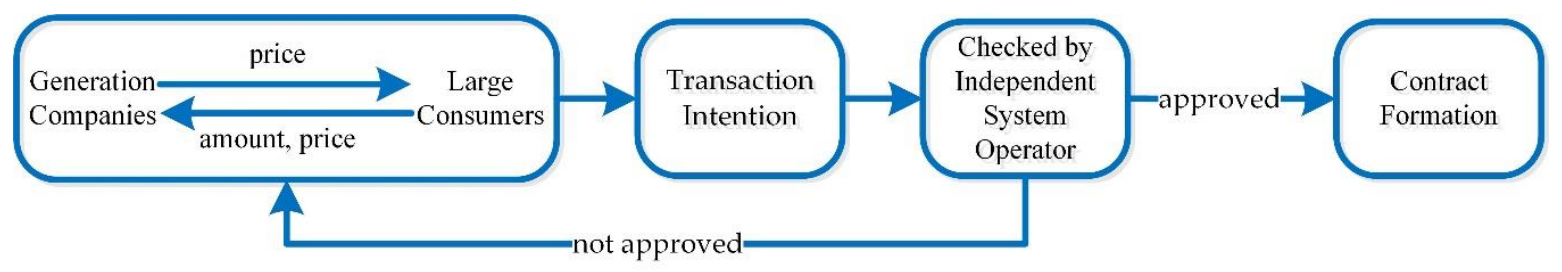

Figure 1. Independent negotiation mode.

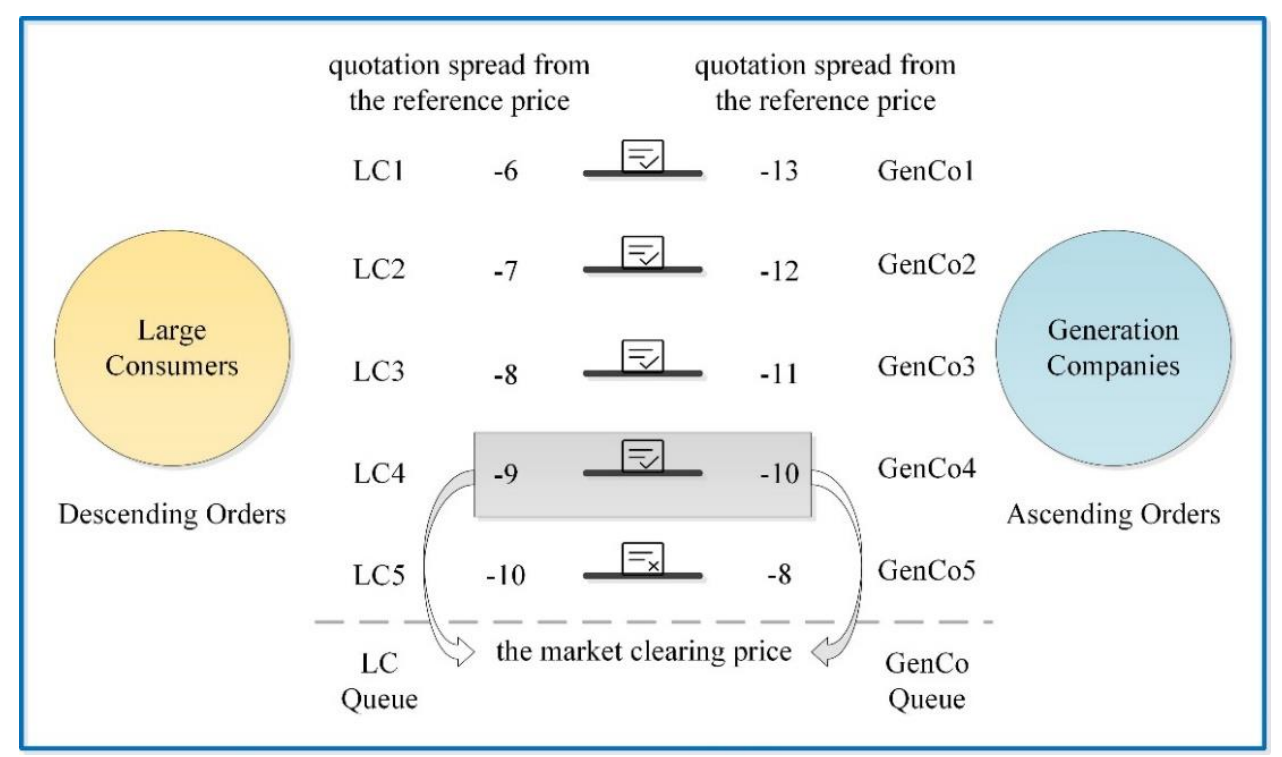

Figure 2. Centralized order matching mode. 


\subsection{Transaction Price of Direct Electricity Procurement}

In the context of direct electricity procurement, there are three negotiating manners: one-to-one, one-to-many, and many-to-many. Among these manners, the most central and foundational one is the one-to-one negotiation. This manner could help clarify the negotiation process and the price of the transaction. In direct electricity procurement between a single LC and a single GenCo, the two sides negotiate for a certain amount of electricity. It is difficult for the two sides to reach an agreement on the transaction price at one time, so they will carry out a game process of bargaining for the transaction price. The bargaining process is often a rotational bidding process, which is a sequential negotiation problem.

Under different manners, LCs and GenCos have different negotiation strategies to achieve their goals due to their different considerations and preferences. In some simple cases, LCs and GenCos only need to consider their own quotation and the quotation of the opponent. In some complex cases, LCs and GenCos need to consider more complex factors, such as the market environment and the impact of their own quotation on the market environment. Although their strategies and considerations are different, they all aim to seek maximum benefits under the constraints of market rules.

Before the negotiations, LCs and GenCos will set two prices according to the trading volume and their own strategies; namely, the initial price and the reserve price. The reserve price means the maximum acceptable electricity price for the LC and the minimum acceptable electricity price for the GenCo. The initial price is the first negotiation price given by participants in the negotiation, which is lower than the reserve price for the LC and higher than the reserve price for the GenCo. In order to get more benefits, LCs will set an initial price well below the reserve price, and GenCos will set an initial price well above the reserve price, as shown in Figure 3. The red shaded area represents the tradable price range for the LC, whereas the blue shaded area represents the tradable price range for the GenCo. Only when the reserve price of the LC is higher than that of the GenCo is it possible for the two sides to reach an agreement.

After entering the negotiation process, the LC and the GenCo constantly adjust their bidding. The LC will gradually increase the offer from the initial price until the reserve price is reached. Instead, the GenCo will gradually reduce the offer from the initial price until the reserve price is reached. Within a certain trading time limit, which is usually set by the ETI, the transaction will be reached when the LC offers more than the GenCo. After the trading time limit is exceeded, if the price offered by the LC is still lower than that offered by the GenCo, the transaction cannot be concluded. For the transaction that can be reached, the negotiated transaction price is between the reserve price of the GenCo and the reserve price of the LC, as shown in the green shaded area in Figure 3.

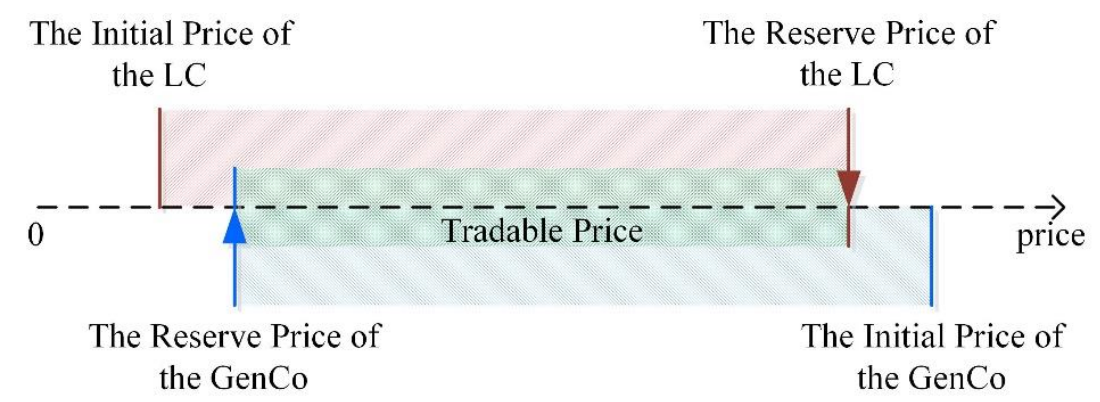

Figure 3. Negotiating price information of LC and GenCo.

\subsection{Description of Risk Preference}

In direct electricity procurement, LCs and GenCos will face some potential risks. On the one hand, participants may miss out on trading opportunities in complex market environments with a large number of members. Due to the different reserve prices of different market participants and the limitation of negotiation time, some of the large number of participants are unable to meet trading 
conditions before the deadline. On the other hand, the transactions reached may actually reduce the benefit because of uncertainty. The spot price volatility caused by uncertainty factors will make the spot price at market-clearing time higher or lower than the negotiated transaction price.

To deal with the potential risks, the participants of the electricity procurement need to adopt some tradeoffs. One of the tradeoffs is between the price and the likelihood of the transaction. For example, if the LC raises the negotiation price significantly, the likelihood of reaching an agreement will increase, but at the same time, the benefits of the transaction will be reduced. Another tradeoff is between the pool trading and the bilateral contracts. Large consumers and GenCos can change the pool/bilateral mix based on their own risk preference to pursue the expected benefits.

\section{Two-Stage Trading Model of Direct Electricity Procurement}

\subsection{Direct Electricity Procurement Involving Multiple Participants}

In the competitive electricity market environment, competition will be introduced on both the power generation side and the demand side, thus forming a trading pattern with multiple participants. In the process of trading, the bidding strategy of the trading subject not only depends on the characteristics of itself and other subjects but is also influenced by the market trading mechanism. Different trading mechanisms lead to different bidding methods and strategies for LCs and GenCos. Reasonable trading mechanism design can help ensure the fairness of the market, promote the completion of a transaction, and protect the interests of both sides.

The existing direct electricity procurements with multiple participants are mostly carried out in the trading modes mentioned above. The independent negotiation is the most fundamental method of direct electricity procurement, and the other modes, including the centralized order matching and listing transactions, are the supplement and extension on this basis. The independent negotiation needs to set up many trade channels for the negotiation between LCs and GenCos. Through different channels, the LC can negotiate with different GenCos to determine the most suitable GenCo and transaction price, and vice versa. This mode leads to the waste of transaction resources for supporting a large number of negotiations and creates unfairness due to the information asymmetry between the two sides. The centralized order matching and listing transactions can save transaction resources. The participants from both sides will submit quotations to the ETI according to their own interests, and the ETI will determine the trading results according to the trading rules. However, this kind of trading mode only provides a single quotation opportunity for each participant in each transaction. When there is a large price gap between the two sides, it is difficult for the participants to complete the transaction efficiently, because they lack the opportunity to adjust the bidding price according to the trading situation.

\subsection{Trading Mechanism Design of Direct Electricity Procurement}

In order to overcome the disadvantages of the existing trading mechanisms, it is necessary to design a trading mechanism which can not only reduce the occupation of transaction resources but also give the participants who have not reached a transaction the opportunity to continue participating in the transaction. Based on the characteristics and requirements of the participants, we propose a novel two-stage trading mechanism of direct electricity procurement, including centralized clearing in the first stage and continuous matching in the second stage. In the first stage, LCs and GenCos submit quotations to the ETI, and then the ETI clears the quotations. In the second stage, within a certain time limit, LCs and GenCos submit quotations round by round. At each round the ETI will clear the market for the LCs and GenCos who meet the trading requirements. This two-stage trading mechanism combines the characteristics of existing market trading mechanisms, such as centralized order matching and listing transactions and integrates the process of game negotiation. It increases the choice range of both sides, speeds up the decision-making process, reduces the trading cost, and improves the trading efficiency. By replacing the direct negotiations between LCs and GenCos with open bidding, 
the problem of information asymmetry is solved, and fairness in the market trading environment is guaranteed.

The trading process of the two-stage trading mechanism is illustrated in Figure 4 . In the first stage, the ETI clears the quotations submitted by LCs and GenCos under the high and low matching rules with a unified clearing price. Large consumers submit bidding packages, including trading price and volume, whereas GenCos submit bidding packages, including trading price and the maximum tradable volume. The ETI forms the trading sequence of LCs by sorting the bidding packages from high to low according to the bidding price. Similarly, but in the opposite direction, the trading sequence of GenCos is formed according to the bidding price from low to high. The bidding package of LC with the highest bidding price is paired with the bidding package of GenCo with the lowest bidding price to form a trading pair. The price gap of the trading pair is the bidding price of LC minus the bidding price of GenCo. When the price gap is non-negative, it can be concluded that this trading pair is taking the arithmetic mean value of the bidding price of LC and GenCo as the transaction price. The transaction volume takes the minimum value of the trading volume of the LC and the maximum tradable volume of the GenCo. When the price gap is negative, the transaction of this trading pair cannot be completed. Once the transaction of the trading pair with the non-negative price gap value is completed, the transaction volume shall be removed from the bidding package. Either LC or GenCo with zero tradable volume in the bidding package will be excluded from the trading sequence. The bidding package and trading sequence are then updated. The ETI repeats the above steps for the updated trading sequences until the price gap of the trading pair is negative. The transaction price of the last trading pair is used as the settlement price of all trading pairs that have completed the transaction and released by the ETI as the reference price. If there is no trading pair with a non-negative price gap in this stage, then the arithmetic mean value of all bidding prices of LCs in the sequence and all bidding prices of GenCos in the sequence is released as the reference price.

In the second stage, all LCs and GenCos that did not complete the transaction in the first stage will enter the continuous bidding process. Large consumers and GenCos adjust the bidding price according to the released reference price and submit the updated bidding packages to the ETI. The matching rules are similar to those of the first stage. The trading sequence of LCs is sorted in order of bidding price from high to low, whereas the trading sequence of GenCos is sorted from low to high. A transaction can be concluded when the price gap of the trading pair is non-negative. The clearing rules are different from those of the first stage. The settlement price for each pair that completes the transaction is independent and takes the arithmetic mean value of the bidding price of the LC and the bidding price of the GenCo. The ETI releases the lowest settlement price as the reference price. Based on this reference price, LCs and GenCos adjust their bidding price to enter the next trading round. The ETI generally sets a limit on the number of trading rounds. Within the limit of trading rounds, LCs and GenCos can constantly adjust their bidding price quotations to participate in the trading process. The entire trading process ends up when one of the following conditions is met: all LCs in the trading sequence complete the transaction, all GenCos in the trading sequence complete the transaction, or the trading rounds reach the limit. 


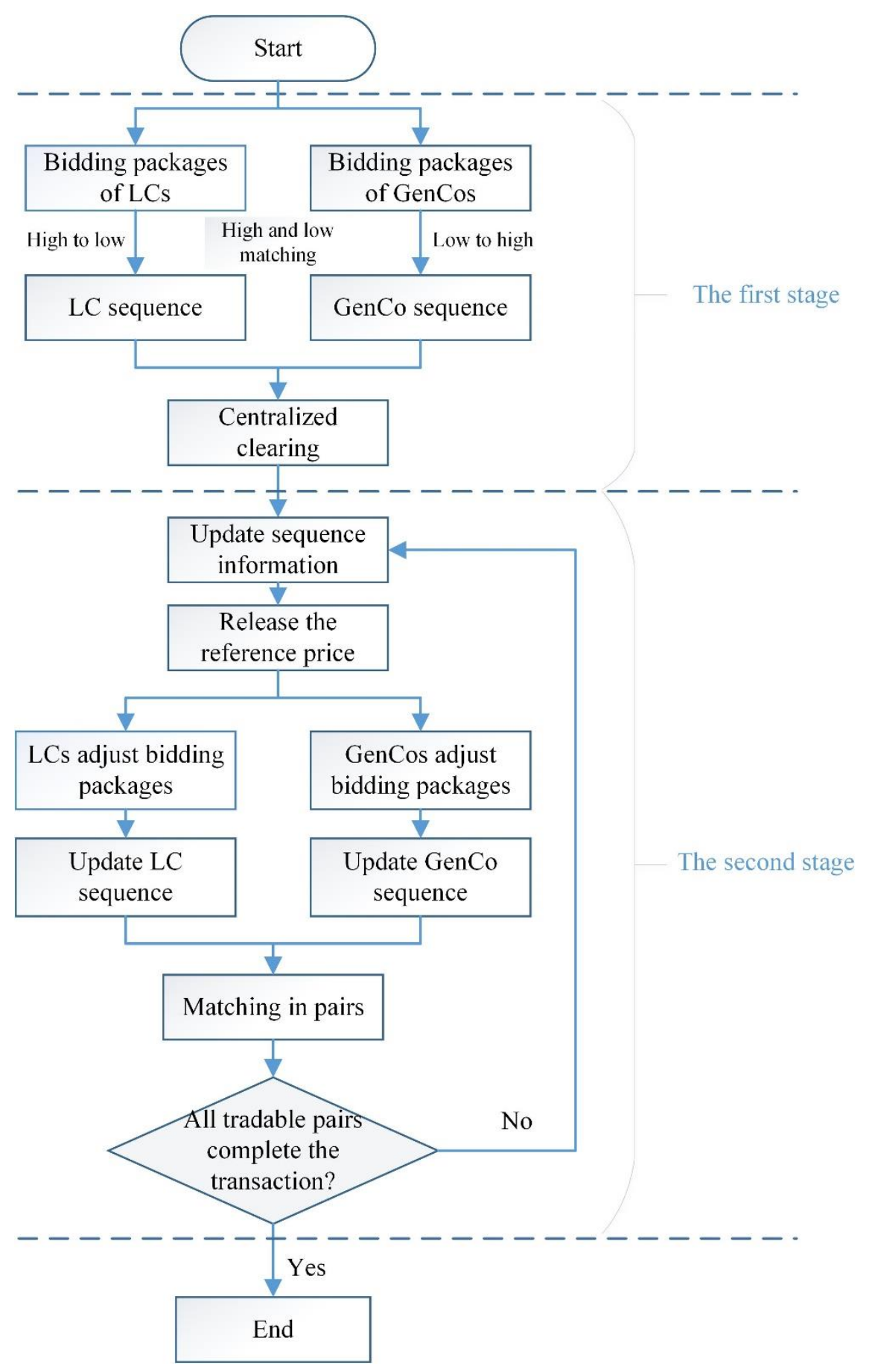

Figure 4. Trading process of the two-stage trading mechanism.

\subsection{Agent-Based Trading Model of Direct Electricity Procurement}

Agent-based simulation has been widely used in multiple domains over the past decade [38,39]. It is a powerful and applicable tool for modeling and analyzing deregulated electricity market [28]. An agent-based trading model of direct electricity procurement is developed in this paper that includes LC Agents, GenCo Agents, and the ETI Agent. The ETI operates the trading platform, designs the trading architecture, and formulates the trading rules to ensure the fairness of direct electricity procurement. In addition to the transaction price of direct electricity procurement, the electricity price paid by the LC also includes the transmission and distribution price. In fact, direct electricity procurements are usually carried out under the same electricity trading institution, involving only 
one utility providing transmission and distribution services with a unified price. In this context, the transmission and distribution price has no impact on the trading process or the bidding strategy, which can be ignored. After the completion of the trading process, the ETI shall submit all the concluded transactions between LCs and GenCos to the ISO for security checks. The transactions that can be verified through security checks will be granted trading authority by the ISO. Large consumers and GenCos actually settle these confirmed transactions.

The ETI Agent operates the trading platform TP, including N LC Agents and M GenCo Agents. The $i$ th LC Agent can be expressed as $\operatorname{con}_{i}, i=1,2, \cdots, N$, and its reserved price is $v_{i}$. Before the trading process begins, the Agent $c o n_{i}$ determines the trading volume $q_{i}$ and the initial bidding price $p_{i}^{0}$ as the bidding package $q p_{i}^{0}$, which is submitted to the TP. The $j$ th GenCo Agent can be expressed as $\operatorname{gen}_{j}, j=1,2, \cdots, M$, and its reserved price is $v_{j}$. Before the trading process begins, the Agent gen $n_{j}$ determines the maximum tradable volume $q_{j}$ and the initial bidding price $p_{j}^{0}$ as the bidding package $q p_{j}^{0}$, which is submitted to the TP.

After the trading process of direct electricity procurement begins, $N$ bidding packages $q p_{i}^{0}$ of LC Agents and $M$ bidding packages $q p_{j}^{0}$ of GenCo Agents participate in the centralized bidding of the first stage. The ETI Agent clears these quotations according to the above-mentioned high and low matching rules and releases the reference price $p_{r}^{0}$. Those LC Agents and GenCo Agents who fail to complete the transaction in the first stage will participate in the continuous bidding in the second stage. The remaining agents adjust the bidding price and submit the updated bidding packages to the TP round by round until the transaction is completed or the limit of trading rounds is reached. In each round, the ETI Agent clears the submitted bidding packages pair by pair and releases the reference price as public information on the TP. The upper limit of trading round $T_{\max }$ is a positive integer set by the ETI Agent. The trading round is denoted by $t=1,2, \cdots, T_{\max }$. For the trading round $t$, the bidding package of $\operatorname{con}_{i}$ is $q p_{i}^{t}=\left\{q_{i}^{t}, p_{i}^{t}\right\}$, where $q_{i}^{t}$ is the trading volume and $p_{i}^{t}$ is the bidding price of $\operatorname{con}_{i}$ at $t$. The bidding package of the Agent $\operatorname{gen}_{j}$ is $q p_{j}^{t}=\left\{q_{j}^{t} p_{j}^{t}\right\}$, where $q_{j}^{t}$ is the tradable volume and $p_{j}^{t}$ is the bidding price of $g e n_{j}$ at $t$. The reference price released by the ETI Agent is $p_{r}^{t}$.

In the first stage, LC Agents and GenCo Agents set an initial bidding price based on their own historical experience and risk preference, $p_{i}^{0}$ and $p_{j}^{0}$, respectively. In the second stage, LC Agents and GenCo Agents adjust the bidding price based on the bidding price of the previous round. Whereas ${ }^{c o n} n_{i}$ gradually increases the bidding price with the adjustment range $\Delta p_{i}$, gen $n_{j}$ gradually reduces the bidding price with the adjustment range $\Delta p_{j}$, as in

$$
\begin{aligned}
& p_{i}^{t+1}=p_{i}^{t}+\Delta p_{i}, \\
& p_{i}^{t+1}=p_{i}^{t}+\Delta p_{i} .
\end{aligned}
$$

The adjustment range of the LC Agent and GenCo Agent can also be expressed as

$$
\begin{aligned}
& \Delta p_{i}=\theta_{i} * p_{i}^{0}, \\
& \Delta p_{j}=\theta_{j} * p_{j}^{0},
\end{aligned}
$$

where $\theta_{i}$ is the bidding coefficient of $\operatorname{con}_{i}$ and $\theta_{j}$ is the bidding coefficient of $g^{2} n_{j}$.

The value of the bidding coefficient is determined by the trading strategy of the agent. In each round, the LC Agent and the GenCo Agent will adjust the bidding coefficient according to the reference price and the trading strategy. When adjusting the bidding coefficient, the agent needs to seek a tradeoff between the possibility and the benefit of a transaction. For example, if $\operatorname{con}_{i}$ adjusts $\theta_{i}$ to a large value in a certain round, which means the bidding price $p_{i}^{t}$ will be relatively high, $\operatorname{con}_{i}$ will have a higher probability of completing the transaction compared with other LC Agents. Although $\operatorname{con}_{i}$ is more likely to complete the transaction with the GenCo Agent, the benefit will be reduced due to the higher transaction price. 
Large consumer Agents and GenCo Agents can judge the changing trend of a trading situation according to the reference price information released by the ETI Agent. On the one hand, the reference price reflects the transaction price. The agent is more likely to conclude the transaction if the bidding price is closer to the reference price. On the other hand, the change of reference price reflects the bidding strategy of all participants to some extent. If the reference price changes significantly from the previous round, it indicates that some agents have adopted a more aggressive bidding strategy. On the contrary, if the change of reference price is not obvious, it means all agents choose a conservative bidding strategy. Thus, the reference price will be adopted by agents to improve the bidding strategy. Specifically, LC Agents and GenCo Agents adjust the bidding coefficient according to the change range of the reference price after the end of each bidding round. The reference price released by the ETI Agent at round $t$ is $p_{r}^{t}$. The change range of the reference price is $\Delta p_{r}^{t}=p_{r}^{t}-p_{r}^{t-1}$.

Considering the influence of reference price, the $i$ th LC Agent $\operatorname{con}_{i}$ updates the bidding coefficient $\theta_{i}$ according to Formula (5) and the $j$ th GenCo Agent $g^{2} n_{j}$ updates the bidding coefficient $\theta_{j}$ according to Formula (6) after $p_{r}^{t}$, the reference price for round $t$, is released.

$$
\begin{aligned}
& \theta_{i} \leftarrow \theta_{i} * \lambda_{i} * \frac{p_{i}^{t-1}-p_{i}^{t-2}}{p_{i}^{t}-p_{i}^{t-1}} * \frac{\Delta p_{r}^{t}}{\Delta p_{r}^{t-1}}, \\
& \theta_{j} \leftarrow \theta_{j} * \lambda_{j} * \frac{p_{j}^{t-1}-p_{j}^{t-2}}{p_{j}^{t}-p_{j}^{t-1}} * \frac{\Delta p_{r}^{t}}{\Delta p_{r}^{t-1}},
\end{aligned}
$$

where $\lambda_{i}$ is the risk preference coefficient of $\operatorname{con}_{i}$ and $\lambda_{j}$ is the risk preference coefficient of gen ${ }_{j}$. The risk preference coefficient is a constant value around 1 . A value greater than 1 indicates that the agent is more inclined to obtain trading opportunities; a value less than 1 indicates that the agent is more inclined to obtain trading benefits; the value equal to 1 indicates that the agent attaches equal importance to trading opportunities and trading benefits.

\section{Results}

Direct electricity procurement has been implemented in some electricity markets, which provides us with some valuable empirical evidence. According to the practical experience of direct electricity procurement, the number of LC Agents participating in direct electricity procurement is usually larger than the number of GenCo Agents, and the maximum tradable electricity volume of GenCo Agents is generally higher than the trading volume of LC Agents. According to the above practical characteristics and historical data of direct electricity procurement in a certain area of China, we set the parameters of this case study. In this case, there are 10 LC Agents, 5 GenCo Agents, and one ETI Agent. The maximum number of trading rounds of the second stage is 30 . The detailed parameters of the LC Agents are shown in Table 1, and the detailed parameters of the GenCo Agents are shown in Table 2. Security checks are generally carried out after the completion of all transactions with no direct impact on the trading process or bidding strategy. Therefore, the process of safety checking is ignored in this paper. The risk preference of all agents is set to 1 , which means agents seek a balance between trading opportunities and benefits. The trading process is implemented by JAVA language programming based on JADE platform.

The LC Agents and GenCo Agents participate in the first stage of direct electricity procurement with the initial price. The ETI Agent sorts the bidding packages and clears the bidding pairs that meet the trading requirements. The trading sequence of LC Agents sorted according to the bidding price from high to low and the trading sequence of GenCo Agents sorted according to the bidding price from low to high are matched by the ETI Agent to form trading pairs, as shown in Table 3. 
Table 1. Detailed parameters of LC Agents.

\begin{tabular}{ccccc}
\hline LC Agent & $\begin{array}{c}\text { Trading Volume } \\
\text { (MWh) }\end{array}$ & $\begin{array}{c}\text { Initial Bidding } \\
\text { Price (RMB/MWh) }\end{array}$ & $\begin{array}{c}\text { Reserve Price } \\
\text { (RMB/MWh) }\end{array}$ & $\begin{array}{c}\text { Bidding } \\
\text { Coefficient }\end{array}$ \\
\hline con1 & 1200 & 400 & 320 & 0.01 \\
con2 & 1800 & 410 & 360 & 0.005 \\
con3 & 450 & 440 & 370 & 0.008 \\
con4 & 3700 & 420 & 300 & 0.015 \\
con5 & 1100 & 390 & 330 & 0.005 \\
con6 & 1300 & 430 & 310 & 0.015 \\
con7 & 1500 & 400 & 310 & 0.01 \\
con8 & 600 & 400 & 350 & 0.002 \\
con9 & 200 & 410 & 380 & 0.002 \\
con10 & 350 & 420 & 340 & 0.008 \\
\hline
\end{tabular}

Table 2. Detailed parameters of GenCo Agents.

\begin{tabular}{ccccc}
\hline $\begin{array}{c}\text { GenCo } \\
\text { Agent }\end{array}$ & $\begin{array}{c}\text { Trading Volume } \\
\text { (MWh) }\end{array}$ & $\begin{array}{c}\text { Initial Bidding } \\
\text { Price (RMB/MWh) }\end{array}$ & $\begin{array}{c}\text { Reserve Price } \\
\text { (RMB/MWh) }\end{array}$ & $\begin{array}{c}\text { Bidding } \\
\text { Coefficient }\end{array}$ \\
\hline gen1 & 3100 & 460 & 330 & 0.01 \\
gen2 & 4200 & 420 & 340 & 0.008 \\
gen3 & 2700 & 390 & 310 & 0.008 \\
gen4 & 1500 & 400 & 320 & 0.008 \\
gen5 & 1300 & 360 & 300 & 0.005 \\
\hline
\end{tabular}

Table 3. Differential price pair of centralized bidding stage.

\begin{tabular}{cccccc}
\hline $\begin{array}{c}\text { LC } \\
\text { Agent }\end{array}$ & $\begin{array}{c}\text { Trading } \\
\text { Volume } \\
\text { (MWh) }\end{array}$ & $\begin{array}{c}\text { Initial Bidding } \\
\text { Price } \\
\text { (RMB/MWh) }\end{array}$ & GenCo Agent & $\begin{array}{c}\text { Trading } \\
\text { Volume } \\
\text { (MWh) }\end{array}$ & $\begin{array}{c}\text { Initial Bidding } \\
\text { Price } \\
\text { (RMB/MWh) }\end{array}$ \\
\hline con9 & 200 & 380 & gen5 & 1300 & 360 \\
con3 & 450 & 370 & gen3 & 2700 & 390 \\
con2 & 1800 & 360 & gen4 & 1500 & 400 \\
con8 & 600 & 350 & gen2 & 4200 & 420 \\
con10 & 350 & 340 & gen1 & 3100 & \\
con5 & 1100 & 330 & & & \\
con1 & 1200 & 320 & & & \\
con6 & 1300 & 310 & & & \\
con7 & 1500 & 310 & & & \\
con4 & 3700 & 300 & & & \\
\hline
\end{tabular}

Three LC Agents con9, con3, and con2 in the LC bidding sequence have a higher bidding price than the GenCo Agent gen5 in the GenCo bidding sequence. This means that the price gaps of these bidding pairs are non-negative and meet trading conditions. The con9 is the first to complete the transaction with gen5. After the transaction is completed, con9 is moved out of the bidding sequence, and the tradable volume of gen 5 is updated to $1100 \mathrm{MWh}$. Next, con3 completes the transaction with gen 5 and is subsequently moved out of the bidding sequence. The tradable volume of gen 5 becomes $650 \mathrm{MWh}$ after this transaction. When the con2 trades with gen5, the demand volume of con2 is $1800 \mathrm{MWh}$, which is larger than the tradable volume of gen5. Therefore, the transaction volume between con2 and gen5 is $650 \mathrm{MWh}$. Subsequently, gen5 is moved out of the GenCo bidding sequence and the trading volume of con 2 is updated to $1150 \mathrm{MWh}$. At this point, the first agent of the LC bidding sequence is con 2 with the trading volume of $1150 \mathrm{MWh}$ and the bidding price of $360 \mathrm{RMB} / \mathrm{MWh}$. The first agent of the GenCo bidding sequence is gen 3 with the tradable volume of $2700 \mathrm{MWh}$ and the bidding price of $390 \mathrm{RMB} / \mathrm{MWh}$. As the price gap of the first bidding pair is negative, no more agents could continue with completing the transaction. This is the end of the first trading stage, and the ETI 
Agent releases the market clearing price of the first stage, which is $360 \mathrm{RMB} / \mathrm{MWh}$. The Agents con9, con3, con2, and gen5, which have completed the transaction in the first stage, will settle the transaction according to this price.

In the second stage, the Agents con9, con3, and gen5 are removed from the bidding sequence because their trading volume has been cleared. The Agent con 2 will continue to be in the bidding sequence because it has only completed the transaction for a portion of its trading volume, leaving $1150 \mathrm{MWh}$. The initial trading volume information of the bidding sequences in the second stage is shown in Table 4. Based on the initial bidding price in the first stage, the remaining agents in the bidding sequence adjust the bidding price round by round to participant in the second trading stage. The initial bidding price and bidding strategies of these agents are different, so the bidding price curves are also different. In each round, the ETI Agent clears the bidding pairs that meet the trading conditions and releases the reference price. The bidding price curves of agents and the trading results are shown in Figure 5.

Table 4. Agent information participating in continuous bidding stage.

\begin{tabular}{cccc}
\hline LC Agent & Trading Volume (MWh) & GenCo Agent & Trading Volume (MWh) \\
\hline con2 & 1150 & gen3 & 2700 \\
con8 & 600 & gen4 & 1500 \\
con10 & 350 & gen2 & 4200 \\
con5 & 1100 & gen1 & 3100 \\
con1 & 1200 & & \\
con6 & 1300 & & \\
con7 & 1500 & & \\
con4 & 3700 & & \\
\hline
\end{tabular}

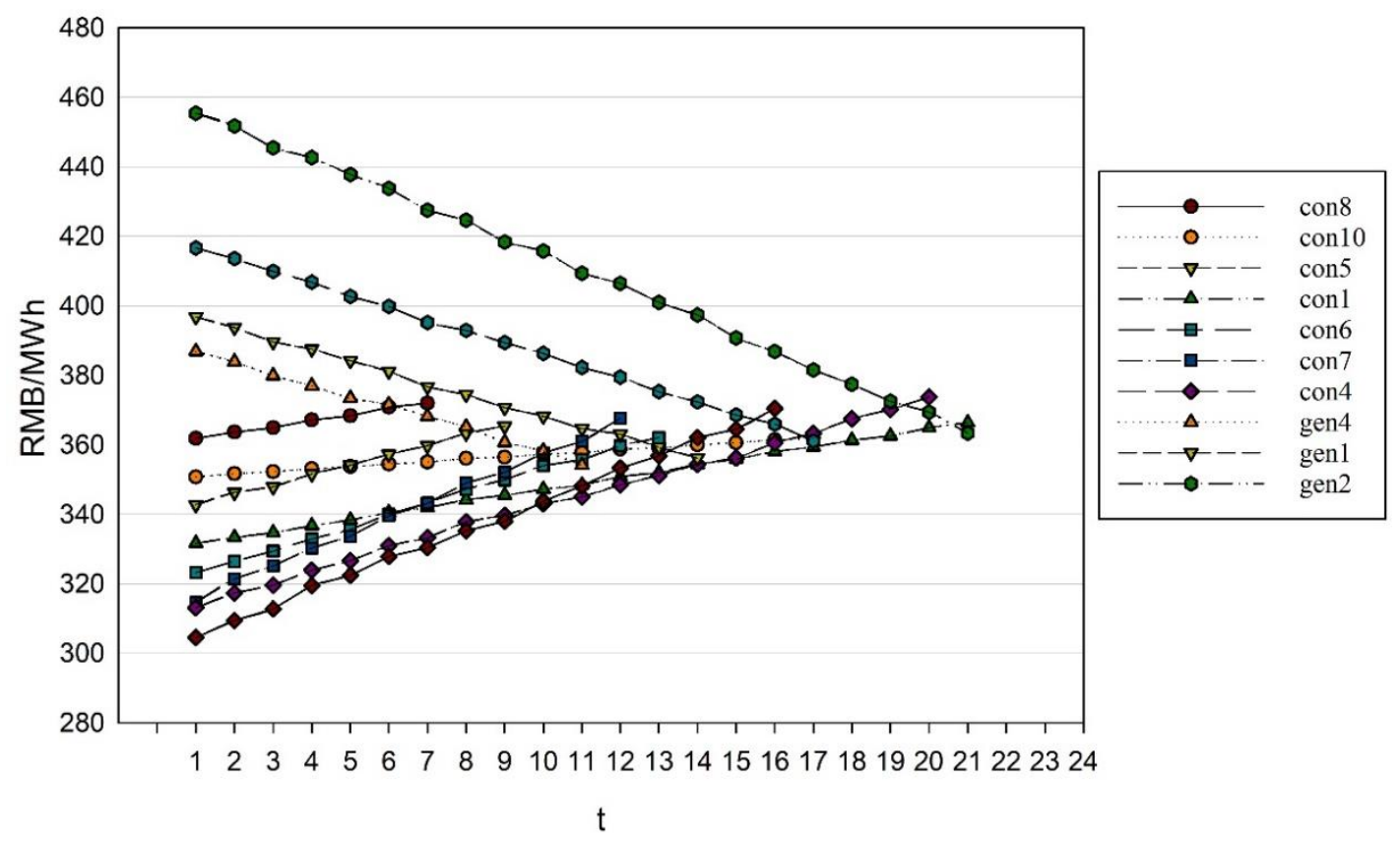

Figure 5. Bidding price curves of Agents and the trading results.

As shown in Figure 5, different LC Agents and GenCo Agents have different bidding strategies, leading to the variation of transaction round and price. Some LC Agents have a lower initial bidding price, which means that they are closer to the bottom of the bidding sequence and will complete the transaction later than other agents. However, due to the adjustment of the bidding strategy, the change range of the bidding price increases with the bidding round, enabling these agents to reach the transaction conditions before other agents. In the 21st round of the second stage, all LC 
Agents complete the transaction; thus, the whole trading process of direct electricity procurement is terminated.

The trading results of direct electricity procurement, including the bidding results of the two stages, are shown in Table 5. From the results, it can be seen that all 10 LC Agents and 5 GenCo Agents participate in the trading process in the first stage, whereas in the second stage, there are $7 \mathrm{LC}$ Agents and 4 GenCo Agents. The settlement price in the first stage is a unified market clearing price of $360 \mathrm{RMB} / \mathrm{MWh}$. In the second stage, the first trading pair that complete the transaction are con2 and gen 3 at the 7th round with a trading price of $370.06 \mathrm{RMB} / \mathrm{MWh}$. At the 14th round, the bidding price of con 8 and con 4 are both higher than that of gen4, which means that the two LC Agents both have the opportunity to complete the transaction. However, the bidding price of con 4 at this round is 362.04 RMB/MWh, which is higher than the $359.94 \mathrm{RMB} / \mathrm{MWh}$ of con8, making con4 rank higher in the bidding sequence to complete the transaction with gen 4 before con8. At the 21st round, con 5 and gen1, as the last trading pair, complete the transaction with a trading volume of $1100 \mathrm{MWh}$. After this, gen1 still has a tradable volume of $600 \mathrm{MWh}$, which fails to complete the transaction because the trading process is over, with all LC Agents having completed the transaction.

Table 5. Trading results of direct electricity procurement.

\begin{tabular}{ccccc}
\hline Bidding Round & LC Agent & GenCo Agent & Trading Volume & $\begin{array}{c}\text { Transaction Price } \\
\text { (RMB/MWh) }\end{array}$ \\
\hline 0 & con9 & gen5 & 200 & 360 \\
0 & con3 & gen5 & 450 & 360 \\
0 & con2 & gen5 & 650 & 360 \\
7 & con2 & gen3 & 1150 & 370.06 \\
9 & con10 & gen3 & 350 & 363.04 \\
11 & con6 & gen3 & 1200 & 357.55 \\
12 & con6 & gen4 & 100 & 365.28 \\
13 & con1 & gen4 & 1200 & 361.27 \\
14 & con4 & gen4 & 200 & 360.66 \\
16 & con4 & gen2 & 3500 & 368.19 \\
17 & con8 & gen2 & 600 & 361.43 \\
17 & con7 & gen2 & 100 & 362.14 \\
20 & con7 & gen1 & 1400 & 371.58 \\
21 & con5 & gen1 & 1100 & 364.84 \\
\hline
\end{tabular}

The average market price (AMP) — that is, the total amount of transaction value divided by the total amount of the transaction volume - can measure the overall trading situation of direct electricity procurement. According to the trading results, the AMP of the first stage is $360 \mathrm{RMB} / \mathrm{MWh}$, and the AMP of the second stage is $365.79 \mathrm{RMB} / \mathrm{MWh}$. For the whole trading process including two stages, the AMP is $365.18 \mathrm{RMB} / \mathrm{MWh}$, which is lower than that of the second stage. If there is only a centralized bidding process like the one in the first stage, most agents cannot complete the transaction. If there is only a continuous bidding process like that in the second stage, the AMP is $365.52 \mathrm{RMB} / \mathrm{MWh}$ with an increase in the AMP of the proposed two-stage trading mechanism. To conclude, the first stage prevents agents from making an unreasonable bidding price, and the second stage gives agents the opportunity to adjust the bidding price to complete the transaction; in addition, it can also promote the reduction of the AMP.

\section{Conclusions}

Electricity markets have been established in many countries around the world, many of which are still in the stage of development and transition. Each electricity market pursues the ultimate goal of perfect market design. To complete the transition and achieve the key objectives of perfect market design, market designers often choose bilateral contracts as a pilot for electricity market reform, among which the most widely adopted type is direct electricity procurement of large consumers. 
The trading mechanism for direct electricity procurement is critical because it lays the foundation for the exploration of formulating the strategy optimization model and the succeeding solution; however, the existing trading mechanisms of direct electricity procurement struggle to cope with new challenges. Coping with the aforementioned concerns, we propose a novel trading mechanism which includes two bidding stages to provide a new choice for market designers and participants.

With multi-agent simulation, which is a powerful and suitable tool for modeling and analyzing deregulated electricity markets, we develop an agent-based model including 10 LC Agents and 5 GenCo Agents to illustrate the feasibility of the proposed mechanism. The simulation results show that, under the proposed trading mechanism, LCs and GenCos can quickly complete the transaction in the first stage or can also achieve their goals by adjusting the bidding price in the second stage. The mechanism takes into account both the fairness and efficiency of direct electricity procurement. In addition, the mechanism helps to reduce the average market price, which is conducive to studying the impact of market mechanism on prices. In conclusion, the proposed trading mechanism can be adopted by market designers as a practical trading rule and by researchers as a simulation tool to study issues related to direct electricity procurement.

Author Contributions: Conceptualization, J.Z. and Z.H.; methodology, J.Z. and Y.Z.; software, J.Z.; validation, Y.Z.; formal analysis, J.Z. and Y.Z.; investigation, J.Z. and H.W.; resources, Y.Z., M.Y., and Z.H.; data curation, J.Z.; writing —original draft preparation, J.Z.; writing-review and editing, J.Z., Y.Z., M.Y., and Z.H.; visualization, J.Z.; supervision, Z.H.; project administration, Z.H.; funding acquisition, Y.Z.

Funding: This research received no external funding.

Conflicts of Interest: The authors declare no conflict of interest.

\section{References}

1. Yang, Y.; Bao, M.; Ding, Y.; Song, Y.; Lin, Z.; Shao, C. Review of information disclosure in different electricity markets. Energies 2018, 11, 3424. [CrossRef]

2. Litvinov, E.; Zhao, F.; Zheng, T. Electricity Markets in the United States: Power Industry Restructuring Processes for the Present and Future. IEEE Power Energy Mag. 2019, 17, 32-42. [CrossRef]

3. Hobbs, B.F.; Oren, S.S. Three Waves of U.S. Reforms: Following the Path of Wholesale Electricity Market Restructuring. IEEE Power Energy Mag. 2019, 17, 73-81. [CrossRef]

4. Hogan, W.W. Market design practices: Which ones are best? IEEE Power Energy Mag. 2019, 17, 100-104. [CrossRef]

5. Dagoumas, A. Impact of Bilateral Contracts on Wholesale Electricity Markets: In a Case Where a Market Participant Has Dominant Position. Appl. Sci. 2019, 9, 382. [CrossRef]

6. Qing, X.I.A.; Yang, B.; Haiwang, Z. Institutional design and suggestions for promotion of direct electricity purchase by large consumers in China. Autom. Electr. Power Syst. 2013, 37, 1-7.

7. Lopes, F.; Algarvio, H.; Coelho, H.; Lopes, F. Bilateral contracting in multi-agent electricity markets: Negotiation strategies and a case study. In Proceedings of the 2013 10th International Conference on the European Energy Market (EEM), Stockholm, Sweden, 27-31 May 2013; pp. 1-8.

8. Conejo, A.J.; Contreras, J.; Espínola, R.; Plazas, M.A. Forecasting electricity prices for a day-ahead pool-based electric energy market. Int. J. Forecast. 2005, 21, 435-462. [CrossRef]

9. Algarvio, H.; Lopes, F. Risk Management and Bilateral Contracts in Multi-agent Electricity Markets. Comput. Netw. 2014, 430, 297-308.

10. Bharti, D.; De, M. A new graph theory based loss allocation framework for bilateral power market using diakoptics. Int. J. Electr. Power Energy Syst. 2016, 77, 395-403. [CrossRef]

11. Marí, L.; Nabona, N.; Pagès-Bernaus, A. Medium-term power planning in electricity markets with pool and bilateral contracts. Eur. J. Oper. Res. 2017, 260, 432-443. [CrossRef]

12. Tang, Y.; Ling, J.; Wu, C.; Chen, N.; Liu, X.; Gao, B. Game-Theoretic Optimization of Bilateral Contract Transaction for Generation Companies and Large Consumers with Incomplete Information. Entropy 2017, 19, 272. [CrossRef] 
13. Aalami, H.A.; Nojavan, S. Energy storage system and demand response program effects on stochastic energy procurement of large consumers considering renewable generation. IET Gener. Transm. Distrib. 2015, 10, 107-114. [CrossRef]

14. Foley, A.; Gallachóir, B.Ó.; Hur, J.; Baldick, R.; McKeogh, E.; Foley, A. A strategic review of electricity systems models. Energy 2010, 35, 4522-4530. [CrossRef]

15. Zhong, P.; Zhang, W.; Xu, B. A risk decision model of the contract generation for hydropower generation companies in electricity markets. Electr. Power Syst. Res. 2013, 95, 90-98. [CrossRef]

16. Hatami, A.R.; Seifi, H.; Sheikh-El-Eslami, M.K. Optimal selling price and energy procurement strategies for a retailer in an electricity market. Electr. Power Syst. Res. 2009, 79, 246-254. [CrossRef]

17. Shinde, P.U.; Deshmukh, S.R. Risk management in electricity market by portfolio optimization. In Proceedings of the 2014 Annual IEEE India Conference (INDICON), Pune, India, 11-13 December 2014; pp. 1-6.

18. Mathuria, P.; Bhakar, R. Info-Gap Approach to Manage GenCo's Trading Portfolio with Uncertain Market Returns. IEEE Trans. Power Syst. 2014, 29, 2916-2925. [CrossRef]

19. Lorca, Á.; Prina, J. Power portfolio optimization considering locational electricity prices and risk management. Electr. Power Syst. Res. 2014, 109, 80-89. [CrossRef]

20. Zarif, M.; Javidi, M.H.; Ghazizadeh, M.S. Self-Scheduling of Large Consumers with Second-Order Stochastic Dominance Constraints. IEEE Trans. Power Syst. 2013, 28, 289-299. [CrossRef]

21. Zare, K.; Moghaddam, M.P.; el Eslami, M.K.S. Demand bidding construction for a large consumer through a hybrid IGDT-probability methodology. Energy 2010, 35, 2999-3007. [CrossRef]

22. Farham, H.; Mohammadian, L.; Alipour, H.; Pouladi, J. Energy procurement of large industrial consumer via interval optimization approach considering peak demand management. Sustain. Cities Soc. 2019, 46, 101421. [CrossRef]

23. Mathuria, P.; Bhakar, R. Large consumer's purchase portfolio optimization in electricity market. In Proceedings of the 2016 IEEE 6th International Conference on Power Systems (ICPS), New Delhi, India, 4-6 March 2016; pp. 1-5.

24. Green, R. The Electricity Contract Market in England and Wales. J. Ind. Econ. 1999, 47, 107-124. [CrossRef]

25. Rabinovich, Z.; Naroditskiy, V.; Gerding, E.H.; Jennings, N.R. Computing pure Bayesian-Nash equilibria in games with finite actions and continuous types. Artif. Intell. 2013, 195, 106-139. [CrossRef]

26. Bower, J.; Bunn, D. A Model-Based Comparison of Pool and Bilateral Market Mechanisms for Electricity Trading; London Business School: London, UK, May 1999.

27. Bompard, E.; Huang, T.; Yang, L. Market Equilibrium under Incomplete and Imperfect Information in Bilateral Electricity Markets. IEEE Trans. Power Syst. 2011, 26, 1231-1240. [CrossRef]

28. Vasiljevska, J.; Douw, J.; Mengolini, A.; Nikolic, I. An Agent-Based Model of Electricity Consumer: Smart Metering Policy Implications in Europe. J. Artif. Soc. Soc. Simul. 2017, 20, 12. [CrossRef]

29. An, B.; Gatti, N.; Lesser, V. Alternating-offers bargaining in one-to-many and many-to-many settings. Ann. Math. Artif. Intell. 2016, 77, 67-103. [CrossRef]

30. Alikhanzadeh, A.; Irving, M. Bilateral electricity market theory based on conjectural variations equilibria. In Proceedings of the 2011 8th International Conference on the European Energy Market (EEM), Zagreb, Croatia, 25-27 May 2011; Volume 11, pp. 99-104.

31. Yu, N.; Tesfatsion, L.; Liu, C.C. Financial bilateral contract negotiation in wholesale electricity markets using Nash bargaining theory. IEEE Trans. Power Syst. 2012, 27, 251-267. [CrossRef]

32. Rashedi, N.; Tajeddini, M.A.; Kebriaei, H. Markov game approach for multi-agent competitive bidding strategies in electricity market. IET Gener. Transm. Distrib. 2016, 10, 3756-3763. [CrossRef]

33. Fabra, N.; von der Fehr, N.-H.; Harbord, D. Modeling electricity auctions. Electr. J. 2002, 15, 72-81. [CrossRef]

34. Fabra, N.; Fehr, N.-H.; Harbord, D. Designing electricity auctions. RAND J. Econ. 2006, 37, 23-46. [CrossRef]

35. Nielsen, S.; Sorknæs, P.; Østergaard, P.A. Electricity market auction settings in a future Danish electricity system with a high penetration of renewable energy sources-A comparison of marginal pricing and pay-as-bid. Energy 2011, 36, 4434-4444. [CrossRef]

36. Zhang, J.; Hu, Z.; Zheng, Y.; Zhou, Y.; Wan, Z. Sectoral Electricity Consumption and Economic Growth: The Time Difference Case of China, 2006-2015. Energies 2017, 10, 249. [CrossRef] 
37. Lei, N.; Chen, L.; Sun, C.; Tao, Y. Electricity Market Creation in China: Policy Options from Political Economics Perspective. Sustainability 2018, 10, 1481. [CrossRef]

38. Cocco, L.; Tonelli, R.; Marchesi, M. An Agent-Based Artificial Market Model for Studying the Bitcoin Trading. IEEE Access 2019, 7, 42908-42920. [CrossRef]

39. Garcia-Magarino, I.; Lacuesta, R.; Lloret, J. Agent-Based Simulation of Smart Beds With Internet-of-Things for Exploring Big Data Analytics. IEEE Access 2017, 6, 366-379. [CrossRef]

(C) 2019 by the authors. Licensee MDPI, Basel, Switzerland. This article is an open access article distributed under the terms and conditions of the Creative Commons Attribution (CC BY) license (http://creativecommons.org/licenses/by/4.0/). 